\title{
The influence of competitive pressure on manufacturer internal information integration
}

\author{
José Moyano-Fuentes $^{\mathrm{a} *}$ and Pedro-José Martínez-Jurado ${ }^{\mathrm{b}}$ \\ ${ }^{a}$ Department of Business Organization, Marketing and Sociology, University of Jaén, Linares, Spain; ${ }^{b}$ Defence University Centre, \\ University of Zaragoza, Zaragoza, Spain
}

(Received 31 March 2015; accepted 9 December 2015)

\begin{abstract}
Research on competitive pressure plays an important part in understanding a firm's behaviour in its changing environment. This paper provides an empirical contribution to the knowledge of the relationship between competitive pressure and internal information integration in this area by focusing on manufacturer internal information integration. The findings show that the degree of manufacturer internal information can be explained by the competitive strength of the largest firm in the industry. From a management perspective, the results indicate the need to regard the competitive landscape as an additional lever of manufacturer internal information sharing.
\end{abstract}

Keywords: competitive pressure; internal information integration; information integration

\section{Introduction}

Integration information between internal organisational functions is widely acknowledged by researchers to be a contributor to organisational competitiveness (Kantz and Mentzer 1996; Noori and Mavaddat 1998; Rosenzweig, Roth, and Dean 2003) and it is therefore important to understand its determinants. However, there is little empirical research on the effects of situational factors on information integration (Wong, Lai, and Cheng 2012). In the same line, Sousa and Voss (2008) indicate that when the value of a best practice, such as information integration, is supported by empirical evidence, research should shift from justifying its value to understanding the contextual condition under which it is effective.

Additionally, the literature states that research into competitive pressure might make it possible to come to understand firm behaviour, that is firms, far from being atomistic entities, are embedded in a network of relationships that influences their competitive behaviour (Gnyawali and Madhavan 2001; Ketchen, Snow, and Hoover 2004). To be more specific, we base ourselves on the ideas of Porter (1980), who indicates that an understanding of competitive forces enables a strategy to be developed to enhance the company's long-term benefits. Of these competitive forces, stress has been placed on the role that competitive pressure plays in results on the company level, such as the firm's chances of survival (Barnett 1997). The literature also shows that competitive pressure impacts actions that firms take on the internal level and that competitive pressure can be observed to have a positive effect on innovation (Vives 2008) and on the quality management implementation (Fuentes-Fuentes, Llorens-Montes, and Albacete-Sáez 2007), for example.

Moreover, at a meeting in 2005, the International Federation for Information Processing (IFIP) discussed the important role played by enterprise systems in the global economy and the innovative and unique characteristics of Industrial Information Integration Engineering (IIIE) as a scientific subdiscipline. Broadly speaking, IIIE is a set of foundational concepts and techniques that facilitates the industrial information integration process; specifically, IIIE comprises methods for solving problems when developing IT Infrastructure for industrial sectors, especially in the aspect of information integration (Xu 2011, 630).

This all highlights the importance of information integration in manufacturing and the need to find external factors to explain it. We therefore address the following research question based on contingency theory (Lawrence and Lorsch 1967): What relationship exists between external environmental conditions and the degree of internal information integration?

The literature highlights the need to research broader mechanisms and diagnostics for information integration (Campbell and Sankaran 2005; Melnyk, Narashiman, and DeCampos 2014; Regli 2007; Wong, Lai, and Cheng 2012).

\footnotetext{
*Corresponding author. Email: jmoyano@ujaen.es 
It becomes clear from all the above that the literature has still not analysed the role of one important contextual condition in internal information integration: competitive pressure.

At the same time, manufacturers are subject to problems that come from their position in the supply chain, as they do not have access to perfect demand information and, similarly, retailers do not have sufficient information about supply. This is a cause of inefficiency, uncertainties resulting in higher transactional-processing costs and inventory costs, and a lower service level ( $\mathrm{Li}$ et al. 2006). Authors stress the role of information sharing and the quality of information on the internal level to address these problems (Wang, Ye, and Tan 2014).

On the basis of all the above, we formulate theoretically three main hypotheses to investigate whether competitive pressure is related to manufacturer internal information integration in an empirical study based on a survey of industrial sectors in an intermediate position in the supply chain.

Following this introduction, the second section is devoted to the theoretical background to this research and to formulating the hypotheses. The methodology used is subsequently described. The findings are then discussed and, finally, the conclusions are set out.

\section{Theoretical background and hypotheses}

The context in which firms compete affects how they act and respond to each other (Ketchen, Snow, and Hoover 2004). As such, stakeholder pressure has been observed to have a positive effect on internal operations practices (Yu and Ramanathan 2015). On the other hand, companies in an industry need to maintain the flow of resources that come out of the environment in order to keep their structures intact. Given that the conditions of the environment limit the level of resources, as said resources become less available, so the struggle to be able to obtain them intensifies, i.e. competitive pressure increases, making it difficult for most of the companies in the industry to maintain a sufficient flow of information and resources. In this sense, competitive pressure can be defined as the struggle between organisations in any given industry to obtain the limited resources and information required for survival (Carroll and Hannan 2000). There are two approaches for measuring competitive pressure: the number of competitors operating simultaneously in the industry, or competitive intensity (Hannan and Freeman 1989), and the market share held by the largest firm in the industry, or the largest firm's competitive strength (Barnett 1997).

According to Organisational Ecology, competitive pressure depends directly on the number of companies operating simultaneously in an industry. Thus, the frequency and strength of competitive interactions increase with the number of companies in the industry and competitive intensity is therefore directly proportional to the number of companies (Hannan and Freeman 1989). Competitive intensity is defined as a situation where competition is fierce due to the presence of numerous competitors (Auh and Menguc 2005) and has been regarded as a major contributor to the hostility of the operating environment (Zahra and Covin 1995).

According to contingency theory (Lawrence and Lorsch 1967), external fit indicates consistency between an organisational structure and the strategy it pursues to respond to its external environment. As their external environment changes, manufacturers should respond by developing, selecting and implementing strategies to maintain fit (Tushman and Nadler 1978). Thus, the increased intensity of the competition shapes inter-firm knowledge acquisition (Zhou et al. 2014) and has caused organisations to rethink the need for cooperative, mutually beneficial supply chain partnerships (Lambert and Cooper 2000; Wisner and Tan 2000). The goal is to achieve effective and efficient flows of information, products and services, and money and decisions in order to provide maximum value to the customer at low cost and high speed (Frohlich and Westbrook 2001). Recently, Barney (2012) has indicated that supply chain management has the attributes needed to be a source of sustained competitive advantage, such as sharing proactive information with strategic chain partners, for example (Roh, Hong, and Min 2014).

In addition, Regli (2007) underscores the apparent lack of any fundamental progress in information integration. So, although information integration methods have been explored in a variety of ways, there is still much progress to be made that can provide effective methods for information integration (Xu 2014). In this context, Wong, Lai and Cheng (2012) state that further research is required into the effects of environmental conditions on the success of information integration. Furthermore, internal and external information integration play different roles in information integration and both are necessary (Clark 1996; Wheelwright and Bowen 1996); while external information integration recognises the importance of establishing close, interactive relationships with customers and suppliers, internal information integration recognises that the departments and functions within a manufacturer should function as part of an integrated process (Flynn, Huo, and Zhao 2010). Childerhouse and Towill (2011) find that a sequence exists for integrating information, beginning with enhanced internal effectiveness followed by external information integration. For some authors, internal information integration is the main dimension of information integration (Pagell 2004) and focuses on activities within a manufacturer. Internal information integration is the degree to which manufacturers structure their own organisational 
strategies, practices and processes into collaborative, synchronised processes in order to fulfil their customers' requirements (Kantz and Mentzer 1996) and efficiently interact with their suppliers (Flynn, Huo, and Zhao 2010). Internal information integration efforts break down functional barriers and facilitate the sharing of real-time information across key functions (Wong et al. 2007) and is becoming increasingly important as technological advances create new opportunities for new product development and other improvements to processes (Parker and Anderson 2002).

Following agency theory, more competition may induce a higher cost reduction effort through an incentive scheme that is more sensitive to performance (Vives 2008). In an industrial organisation, a rise in competitive pressure increases an individual firm's investments in process innovations to improve efficiency. So, a rise in competitive intensity is found to be what sets more efficient firms apart from less efficient ones and spurs firms on to raise their productivity (Boone 2000) and is positively related to process innovation strategy implementation (Jayaram, Oke, and Prajogo 2014). In dynamic markets with shifting mobility barriers and highly segmented end-user markets, a customer focus is mandatory (Day and Wensley 1988). Moreover, there is a linkage between this focus and performance in contexts characterised by varying levels of competitive intensity (Jaworski and Kohli 1993). In fact, as environmental dynamism increases, so too does the need for internal information integration since more information must be processed between decision-makers to achieve a given level of performance (Rosenzweig, Roth, and Dean 2003). Specifically, cross-functional information sharing is the bond that ties market orientation and stronger supplier relationships together (Martin and Grbac 2003). According to the above, driven by the competitive pressure that exists in the environment, internal information integration could be assumed to be what enables this bond to be created.

Internal information integration breaks down functional barriers and engenders cooperation in order to fulfil customer requirements and leads to improved process efficiency (Saeed, Malhotra, and Grover 2005), synchronised demand management (Stevens 1989), logistics service performance (Germain and Iyer, 2006; Stank, Keller, and Daugherty 2001), better competitive capabilities (Rosenzweig, Roth, and Dean 2003), operational and business performance (Flynn, Huo, and Zhao 2010) and production cost and production flexibility (Wong, Boon-itt, and Wong 2011). A lack of internal information integration may mean that different functions work at cross-purposes and result in efforts being duplicated and resources being wasted (Pagell 2004). To the contrary, optimal internal information integration would correspond to there being extensive data integration among all internal functions.

At the same time, the impact of internal information integration also depends on contextual conditions and it is also required to support JIT production and collaboration between business functions to achieve delivery performance improvements (Wong, Boon-itt, and Wong 2011).

Taken together, all these arguments point to competitive intensity being linked to manufacturer internal information integration, i.e. competitive intensity might foster an integrated customer order fulfilment process by removing internal silos. Information sharing, joint planning and working in close alliance are important elements of this process and can help manufacturers reduce mistakes and waste. Thus, the first hypothesis is formulated as follows:

H1: Competitive intensity is positively related to manufacturer internal information integration.

Competitive intensity states that no single competitor has the capacity or resources to substantially alter the balance of power between firms. Competitive intensity neglects an important component of competitive pressure, namely, the difference in size between the organisations in an industry. The largest competitors are able to significantly alter competitive pressure in the market (Carroll and Hannan 2000). Increased competitive pressure is reflected through tactics such as aggressive pricing, high levels of advertising, product introductions and adding services (Porter 1980). This way, large firms can have a bearing on the competitive pressure of an industry and, therefore, on the chances of survival (Barnet and Amburgey 1990).

On the other hand, Gnyawali and Madhavan (2001) argue that firms' structural properties influence the flow of assets, information and status between industry members. Resource asymmetries occur because of the differential flow of resources between industry members, as well as their differential ability to control such flows. This triggers a situation with varied levels of motivation and ability to take action or respond to the actions of others. In other words, a firm's control over the flow of resources from itself to the members of an industry will affect companies' competitive behaviours, as they will try to enhance their competitive ability by increasing their internal information integration. Our focus on action likelihood and response likelihood is justified by the fact that the lower the likelihood is of competitor response to an action, the greater the advantage (Grimm and Smith 1997). Thus, firms that initiate competitive actions and are able to deter their competitors from responding to those actions enjoy greater advantages as a result of their actions (Gnyawali and Madhavan (2001)).

All this assumes that companies will react with greater intensity to stronger competitors by improving their internal information integration in an attempt to bring down costs and reduce their competitive disadvantage with respect to 
those companies by strengthening their competitive position, whilst at the same time, driving up incremental profit by improving internal information integration, which leads to the second hypothesis being formulated as:

H2: The largest firm's competitive strength is related positively to internal information integration.

As stated, competitive intensity will affect all the companies in an industry equally, regardless of their size. It ignores the fact that organisations can attain environmental carrying capacity, either by an increase in size or by an increase in numbers. Consequently, competitive intensity would be a suitable variable when the environment does not offer opportunities or incentives for growth (Winter 1990). However, in the current environment, when a firm grows in size, the amount of resources that it uses increases, thereby causing a reduction in the chances of survival of those organisations that depend on the same resources. So, the size of an individual large organisation may displace through competition its industry's size in numbers (Winter 1990) or, in other words, competitive intensity.

The greater threat posed by the strongest competitors would thus eclipse the impact exerted by the number of competitors when determining the reaction of a company to contend with the threat. To enhance its chances of succeeding in the struggle with its market-leading competitors, a company would therefore attempt to improve information management at all stages of the supply chain. The role of the strongest rivals compared to the number of competitors needs to be stressed when explaining the degree of internal information integration, as is reflected in the next hypothesis:

H3: The largest firm's competitive strength is more important for explaining internal information integration than competitive intensity.

\section{Methodology}

\subsection{Population and sample}

To test these hypotheses, a population of 2036 manufacturers with a staff of at least 50 employees was taken from all industrial sectors in the DUNS 50000 Database excluding those exclusively associated with extraction activities, refining, editing and recycling, which therefore do not occupy an intermediate position in the supply chain (approach taken by van der Vaart et al. 2012). These are industrial sectors with structural characteristics in keeping with the ideas of Porter (1980), such as relative bargaining power and barriers to entry, inter alia.

The units of analysis were selected by simple random sampling. Fieldwork was conducted during May-September 2012. The final sample was made up of 394 companies (19.4\% response rate) and provided the same number of valid questionnaires.

The questionnaire was pretested with the aid of five internationally recognised researchers in the areas related to the study. As a result of the pretest, several items were recorded, some formal aspects of the questionnaire were tweaked and the wording was simplified and modified in line with the experts' suggestions.

A telephone survey using a computerised system (Computer-Aided Telephone Interviewing, CATI) was used for data gathering. In this type of system, interviewers are aided by the use of a computer. Telephone numbers from a previously loaded database randomly come up onscreen along with the name and address of the firm, and the names of the people in senior management posts that are to be surveyed. The system enables appointments to be arranged with interviewees and, if necessary, a survey that has already been started can be interrupted and resumed later on. The questionnaire was saved in real time, enabling data to be stored and subsequently managed more efficiently (Weeks 1992). Data were gathered by 10 interviewers who had received specific training in the use of the system and in the research objectives and background. On the first day of the survey, the authors also personally supervised the work of the interviewers through direct training and work shadowing on site. All the 10 members of the interview team worked simultaneously for $4 \mathrm{~h} \mathrm{a}$ day throughout the fieldwork period.

The questionnaire was divided into two different areas depending on the key informant. The first section was targeted at the head of management, accounting or finances and included questions on firm performance and the specific characteristics of the environment that the firm operates in. The second section was targeted at the head of supply chain management, logistics or operations management and related to internal information integration. Since there were two different informants in each organisation, it was necessary to make two separate calls at different times for the two sections of the questionnaire to be completed for each company.

We found no evidence of response bias in a comparison of respondents with non-respondents. Thus, there was found to be no significant difference between distribution by manufacturer sales in the population and in the sample. Distribution by firm sales for the population was taken from the DUNS 50000 database, which is the fullest and most reliable database of Spanish firms. Consequently, phone calls were also made to a random selection of manufacturers who did 
not respond to the questionnaire. We did not observe any specific characteristics in those that decided not to participate nor any pattern in the reasons provided by them to justify their refusal to participate. In general terms, there does not seem to be any non-response bias in our sample.

Finally, the responses of early respondents and late respondents were compared (Armstrong and Overton 1977) and no statistically significant differences $(\alpha=0.05)$ were found for any of the variables included in the study, which also provides evidence of no late response bias. In sum, we were confident that the sample used in the study was random and representative of the population.

\subsection{Variables}

Internal information integration is the dependent variable and measured following the construct proposed and tested by Flynn, Huo and Zhao (2010). Internal information integration is the degree to which manufacturers structure their own organisational strategies, practices and processes into a collaborative, synchronised process in order to fulfil their customers' requirements and efficiently interact with their suppliers (Flynn, Huo, and Zhao 2010). Informants were asked to indicate the degree of integration in areas of internal information integration on a scale of $1-7(1=$ not at all; $7=\mathrm{ex}-$ tensive). Table 1 lists all the items included in the original internal information integration scales. Those marked with an asterisk (*) were dropped after a reliability analysis. Results for the exploratory factorial analysis (EFA) are shown. Reliability was tested using Cronbach's alpha $(\alpha)$ with all scores over 0.6 (Bagozzi and Yi 1988). Finally, a confirmatory factorial analysis (CFA) was performed using EQS 6.1 to confirm scale dimensionality and test convergent validity.

Two independent variables were used to capture the competitive pressure in the industry:

Competitive intensity, measured as the number of competitors operating simultaneously in the company's industry. This is in line with the reasoning of Carroll and Hannan (2000), which states that the intensity of competition varies according to the number of organisations operating in an industry.

Largest firm's competitive strength, measured as the market share held by the largest firm in the company's industry. This variable is based on Barnet (1997), who stresses the importance of company size distribution in the industry for competitive pressure.

Control variables were also included in the regression models in order to control for organisational and supply chain characteristics used in the literature with similar objectives to this research (Cagliano, Caniato, and Spina 2006; Sousa and Voss 2008; Swafford, Ghosh, and Murthy 2008). Specifically, the following control variables were used: number of employees (as a measure of organisational size) and organisational age (as a measure of years in operation). The data to compute these measures were obtained from the DUNS 50000 database. Other control variables that were included were: the number of suppliers (as a measure of the degree of complexity of the company's supply), the number of customers (as a measure of customer bargaining power) and sales margin (as a proxy of organisational performance), which were all inquired about in the questionnaire given to informants.

Table 2 presents the descriptive statistics and correlations between the variables used in the analysis. The table shows that there are some significant correlations between the dependent variable and the independent and control variables. As a result, the following analysis will take the latter into account.

Table 1. Scales and factor analysis.

\begin{tabular}{|c|c|c|c|c|c|c|}
\hline \multirow[b]{2}{*}{ Factor } & \multirow[b]{2}{*}{ Variable } & \multicolumn{3}{|l|}{ EFA } & \multicolumn{2}{|l|}{ CFA } \\
\hline & & SFL & $\alpha$ & $\mathrm{EV} \%$ & $\overline{\mathrm{SFL}}$ & $R^{2}$ \\
\hline \multirow{9}{*}{$\begin{array}{l}\text { Internal } \\
\text { information } \\
\text { integration }\end{array}$} & Data integration between internal functions & .80 & \multirow{9}{*}{.84} & \multirow{9}{*}{57.2} & .80 & .65 \\
\hline & Enterprise application integration between internal functions & .77 & & & .77 & 60 \\
\hline & Integrative inventory management & .79 & & & .69 & .48 \\
\hline & Real-time searching of the level of inventory & .69 & & & .57 & .31 \\
\hline & Real-time searching of logistics-related operating data & .75 & & & .65 & .42 \\
\hline & Utilisation of periodic inter-departmental meetings between internal functions.* & & & & & \\
\hline & Use of cross-functional teams in process improvement.* & & & & & \\
\hline & Use of cross-functional teams in new product development. * & & & & & \\
\hline & $\begin{array}{l}\text { Real-time integration and connection between all internal functions from raw } \\
\text { material management through production, shipping and sales }\end{array}$ & .74 & & & .66 & .43 \\
\hline
\end{tabular}


Table 2. Means, standard deviations and Pearson correlation coefficients.

\begin{tabular}{|c|c|c|c|c|c|c|c|c|}
\hline Variable & Mean & SD & 1 & 2 & 3 & 4 & 5 & 6 \\
\hline 1. Firm age & 27.9 & 17.1 & & & & & & \\
\hline 2. Firm size & 188.6 & 266.9 & $.14^{* *}$ & & & & & \\
\hline 3. Number of customers & 1221 & 5331 & .01 & .02 & & & & \\
\hline 4. Number of suppliers & 492 & 1234 & .03 & $.16^{* *}$ & $.10^{*}$ & & & \\
\hline 5. Sales Margin & 4.1 & 1.0 & .04 & .09 & -.03 & .09 & & \\
\hline 6. Competitive intensity & 119 & 655 & -.01 & -.04 & .07 & -.00 & $-.13 *$ & \\
\hline 7. Largest firm's comp. strength & 26.4 & 16.7 & .03 & .07 & .02 & .06 & -.01 & $-.18 *$ \\
\hline
\end{tabular}

Note: $N=394$

*Correlations are significant for $p<0.05$.

$* *$ Correlations are significant for $p<0.01$.

\subsection{Model evaluation}

Hierarchical regression analysis was used to test the hypotheses, as in other studies with similar objectives to those of this research (Flynn, Huo, and Zhao 2010). This descriptive empirical research seeks to find alignment between the research question and the chosen approach, as in this case, according to Bertrand and Fransoo (2002), the primary concern is to create a model that adequately describes the causal relationships that may exist in reality, thus leading to an understanding of the processes going on.

This type of analysis also enables the variance percentage explained by each of the independent variables to be identified individually (Pedhazur and Schmelkin 1991). Table 2 presents the descriptive statistics and correlations between the independent and control variables used in the analysis. To test the three hypotheses, the independent variables were included separately, one by one (Table 3), beginning with the control variables (Model 1). Next, the variable capturing competitive intensity was included (Model 2, H1) followed by the variable measuring the largest firm's competitive strength (Model 3, H2). Finally, the joint effect of competitive intensity and the largest firm's competitive strength was added in Model 4 (H3). Table 3 also scores the contributions made by each independent variable by determining the change in $R^{2}$ and in F-value after each set was included.

\section{Results}

In Model 1, which only includes control variables, the number of customers is observed to negatively impact internal information integration. This would indicate that an increase in customer bargaining power in practice means greater demands on the manufacturer to meet quantities and delivery times and, in the final analysis, a greater degree of com-

Table 3. Linear regression models for the impact of competitive pressure on internal information integration.

\begin{tabular}{|c|c|c|c|c|}
\hline Independent variables & Model 1 & Model 2 & Model 3 & Model 4 \\
\hline Firm age & .06 & .05 & -.03 & -.02 \\
\hline Firm size & .05 & .08 & .08 & .07 \\
\hline Number of customers & $-.13 * *$ & -.04 & -.03 & .04 \\
\hline Number of suppliers & .06 & .05 & -.04 & -.04 \\
\hline Sales Margin & .06 & .05 & .07 & .06 \\
\hline Competitive intensity & & .46 & & -.11 \\
\hline Largest firm's competitive strength & & & $.18^{*}$ & $.15^{*}$ \\
\hline Competitive intensity $\mathrm{x}$ largest firm's competitive strength & & & & -.09 \\
\hline$F$ & $2.53 *$ & 0.88 & $1.38 *$ & $1.74 *$ \\
\hline$R^{2}$ & .03 & $\begin{array}{r}.00 \\
.02\end{array}$ & $\begin{array}{r}1.50 \\
.05\end{array}$ & $\begin{array}{r}1.14 \\
.08\end{array}$ \\
\hline Change in F-value & .64 & & $3.40 *$ & $2.05^{*}$ \\
\hline Change in $R^{2}$ & -.01 & & .03 & .03 \\
\hline
\end{tabular}

Note: Changes in $R^{2}$ are calculated by comparing Models 1, 3 and 4 with Model $2 .{ }^{\text {a }}$ The values are standardised regression coefficients $(\beta \mathrm{s})$.

$* p<0.05$.

$* * p<0.01$. 
pany internal information integration to meet these demands. However, this is not a clear effect, as it becomes non-significant when the independent variables relating to the competitive pressure that the company is subject to are included. Model 2 shows that the competitive intensity of the industry does not influence manufacturer internal information integration. In addition, including this variable does not help explain a company's degree of internal information integration, as the percentage of the total variance fell to a certain extent compared to the model that only includes the control variables. H1 is rejected on the basis of these results.

However, in Model 3, the competitive strength of the largest firm impacts positively on the degree of manufacturer internal information integration $(\beta=0.18, p<0.05)$, which means that $\mathrm{H} 2$ can be accepted as formulated in the theoretical framework. In the last model (Model 4), the joint effect of competitive intensity and the largest firm's competitive strength is added and the only variable that has a significant positive influence on the degree of manufacturer internal information integration is, once more, the largest firm's competitive strength. This variable is shown to have a robust relationship with internal information integration. It is with this last model that the highest $R^{2}$ level is achieved. This finding enables $\mathrm{H} 3$ to test positively and underscores the internal importance that companies give to the existence of larger competitors in their industry over the competitive intensity that exists there. To defend themselves against the industry's largest rivals, companies increase information integration among all their internal functions. Variance inflation factors range between 1.02 and 2.31, showing that multicollinearity is not an issue in any of the models described above (Hair et al. 2009).

\section{Discussion}

Our study finds that competitive pressure is a determinant of internal information integration, and thus emphasises the importance of finding broader mechanisms to explain internal integration, as recently signalled by other studies (Melnyk, Narashiman, and DeCampos, 2014; Wong, Lai, and Cheng 2012). It also adds to the literature that demonstrates that competitive pressure is positively related to significant actions taken on the internal level (Fuentes-Fuentes, LlorensMontes, and Albacete-Sáez 2007; Vives 2008) and to a company's chances of survival (Carroll and Hannan 2000). More specifically, the current study shows that there is a connection between competition among manufacturers in an industry and the cooperation that is produced internally in a manufacturer.

In other respects, our results support the statements made by Winter (1990) to the effect that the size of an individual large organisation may displace its industry's size in numbers through competition. Thus, our findings show the importance of the competitive strength of the industry's largest firm to explain the degree of internal information integration. This is in line with the findings of Gnyawali and Madhavan (2001), who state that the control exerted by the strongest competitors affects companies' competitive behaviour.

The present study demonstrates that the existence of larger rivals is what makes manufacturers try to improve their competitive position and become stronger themselves through knowledge-sharing routines and effective governance. In other words, the fact that major asymmetries exist in the competitive strength of the firms that make up the industry is what drives improvement in competition by enhancing the way that manufacturers structure their strategies, practices and processes in order to fulfil their customers' demands and to interact efficiently with their suppliers. This company orientation towards improving the level of internal information integration is not perceived when the differences or asymmetries between competitors are not envisaged, i.e. when it is assumed that all the companies in an industry generate the same competitive pressure irrespective of their size or, in other words, when a company's internal information integration level does not relate to competitive intensity in the industry.

In other respects, our findings indicate that even though internal information integration seeks to satisfy customers' demands and requirements and to interact efficiently with suppliers, it is not affected by the number of suppliers or customers that a company has. Our results indicate that the quest for effectiveness through internal information integration is contingent upon the existence of strong competitors in terms of market power.

\section{Conclusions and limitations}

Research on competitive pressure plays an important part in understanding a firm's behaviour in its changing environment (Ketchen, Snow, and Hoover 2004) and the relationship between relational ties and knowledge acquisition (Zhou et al. 2014). This paper provides an empirical contribution to the knowledge of the relationship between competitive pressure and internal information integration using reasoning procedures taken from contingency theory and agency theory.

Our key claim is that the structural characteristics of competitive pressure add considerable value to the literature on information integration, which indicates that the competitive interactions that occur in the industry influence competitive action and response. Specifically, we provide new factors to explain internal information integration related to 
competitive pressure that emphasise the influence of market conditions on the development of manufacturer internal information integration. These findings deepen and complement the results of Cao et al. (2015), which indicate that competition has a positive influence of supply chain integration.

From a management perspective, our findings indicate the need to regard the competitive landscape as an additional lever of internal information integration and, by extension, of information integration, as practitioners suggest that internal information integration is a first step towards achieving information integration. More specifically, close crossfunctional coordination is a strategic imperative, as manufacturers are challenged by strong rivals in their industries. Companies will be in a better position to respond to competitors that are a significant threat through internal information integration improving the quality of information and shared decision-making.

This study is not without limitations. It considers the size of the market to be fixed and to have no influence on competitive pressure. This assumption is valid as the analysis was conducted at a specific point in time. Notwithstanding, we propose to carry out longitudinal studies in the future that enable the effect of variations in market size or the degree of product substitutability on competitive pressure to be analysed. Similarly, the use of a quantitative approach to measure internal information integration introduces respondent bias. However, this is not a limitation if we consider that most of the respondents $(75 \%)$ have been in their posts for more than three years and so should possess knowledge of the information requested.

There is also some concern that this study did not include a qualitative component in addition to the quantitative approach. In this respect, future studies should use the two approaches to demonstrate whether internal information integration is based on a cultural change that removes internal silos. More specifically, qualitative research could be used to dig deeper into the role of processes and people in advancing the degree of internal information integration and finding out how the perception of the competitive situation of the industry transfers to an improvement in a firm's internal efficiency. Similarly, qualitative research would also enable the identified internal information integration construct (Eisenhardt 1989) to be developed and the reason why it is important to be understood.

Finally, in the future, it would be interesting to investigate in greater depth the fact that internal information integration correlates negatively with customer numbers. To be more specific, it would be advisable to use some kind of relative measure connected with firm size. In other words, internal information integration could be differently oriented in a small firm with a large number of customers compared to a large firm with a small number of customers. Similarly, research on networks could be cross-referenced with these results. It would therefore be interesting to investigate when the presence of a dominant actor (large market share) in an industry may result in other actors adapting their practice to differentiate their competitiveness from said powerful actor.

\section{Acknowledgements}

The authors gratefully acknowledge the significant contribution made by reviewers to a previous version of this paper.

\section{Disclosure statement}

No potential conflict of interest was reported by the authors.

\section{Funding}

This work was supported by the research project ECO2010-22105-C03-02 of the Spanish Ministry of Economy and Competitiveness.

\section{References}

Armstrong, J. S., and T. S. Overton. 1977. "Estimating Nonresponse Bias in Mail Surveys.” Journal of Marketing Research 14 (3): 396-402.

Auh, S., and B. Menguc. 2005. "Balancing Exploration and Exploitation: The Moderating Role of Competitive Intensity." Journal of Business Research 58 (12): 1652-1661.

Bagozzi, R. P., and Y. Yi. 1988. "On the Evaluation of Structural Equation Models.” Journal of the Academy of Marketing Science 16 (1): 74-94.

Barnet, W. P., and T. L. Amburgey. 1990. "Do Larger Organizations Generate Stronger Competition?" In Organizational Evolution: New Directions, edited by J. V. Sing: 78-102 Newbury Park, CA: Sage.

Barnett, W. P. 1997. "The Dynamics of Competitive Intensity.” Administrative Science Quarterly 42 (1): 128-160. 
Barney, J. B. 2012. "Purchasing, Supply Chain Management and Sustained Competitive Advantage: The Relevance of Resource-based Theory." Journal of Supply Chain Management 48 (2): 3-6.

Bertrand, J. W. M., and J. C. Fransoo. 2002. "Operations Management Research Methodologies Using Quantitative Modeling." International Journal of Operations and Production Management 22 (2): 241-264.

Boone, J. 2000. "Competitive Pressure: The Effects on Investments in Product and Process Innovation." The RAND Journal of Economics 31 (3): 549-569.

Cagliano, R., F. Caniato, and G. Spina. 2006. "The Linkage between Supply Chain Integration and Manufacturing Improvement Programmes." International Journal of Operations and Production Management 26 (3): 282-299.

Campbell, J., and J. Sankaran. 2005. "An Inductive Framework for Enhancing Supply Chain Integration." International Journal of Production Research 46 (16): 3321-3351.

Cao, Z., B. Huo, Y. Li, and X. Zhao. 2015. "Competition and Supply Chain Integration: A Taxonomy Perspective." Industrial Management \& Data Systems 115 (5): 923-950.

Carroll, G. R., and M. T. Hannan. 2000. The Demography of Corporations and Industries. Princeton, NJ: Princeton University Press.

Childerhouse, P., and D. R. Towill. 2011. "Arcs of Supply Chain Integration." International Journal of Production Research 49 (24): 7441-7468.

Clark, K. B. 1996. "Competing through Manufacturing and the New Manufacturing Paradigm: Is Manufacturing Strategy Passé?" Production and Operations Management 5 (1): 42-58.

Day, G. S., and R. Wensley. 1988. "Assessing Advantage: A Framework for Diagnosing Competitive Superiority." Journal of Marketing 52 (2): 1-20.

Eisenhardt, K. M. 1989. "Building Theories from Case Study Research.” Academy of Management Review 14 (4): $532-550$.

Flynn, B. B., B. Huo, and X. Zhao. 2010. "The Impact of Supply Chain Integration on Performance: A Contingency and Configuration Approach." Journal of Operations Management 28 (1): 58-71.

Frohlich, M. T., and R. Westbrook. 2001. "Arcs of Integration: An International Study of Supply Chain Strategies.” Journal of Operations Management 19 (2): 185-200.

Fuentes-Fuentes, M. M., F. J. Llorens-Montes, and C. A. Albacete-Sáez. 2007. "Quality Management Implementation across Different Scenarios of Competitive Structure: An Empirical Investigation.” International Journal of Production Research 45 (13): 2975-2995.

Germain, R., K. N. S. Iyer. 2006. "The Interaction of Internal and Downstream Integration and its Association with Performance." Journal of Business Logistics 27 (2): 29-52.

Gnyawali, D. R., and R. Madhavan. 2001. "Cooperative Networks and Competitive Dynamics: A Structural Embeddedness Perspective." Academy of Management Journal 26 (3): 431-445.

Grimm, C. M., and K. A. Smith. 1997. Strategy as Action. Cincinnati, OH: South-Western.

Hair, J. F., W. C. Black, B. J. Babin, and R. E. Anderson. 2009. Multivariate Data Analysis. 7th ed. Upper Saddle River, NJ: Prentice Hall.

Hannan, M. T., and J. Freeman. 1989. Organizational Ecology. Cambridge: Harvard University Press.

Jaworski, B. J., and A. K. Kohli. 1993. "Market Orientation: Antecedents and Consequences.” Journal of Marketing 57 (3): $53-70$.

Jayaram, J., A. Oke, and D. Prajogo. 2014. "The Antecedents and Consequences of Product and Process Innovation Strategy Implementation in Australian Manufacturing Firms." International Journal of Production Research 52 (15): $4424-4439$.

Kantz, K. B., and J. T. Mentzer. 1996. "Logistics and Interdepartmental Integration." International Journal of Physical Distribution and Logistics Management 26 (8): 6-14.

Ketchen, D. J., C. C. Snow, and V. L. Hoover. 2004. "Research on Competitive Dynamics: Recent Accomplishments and Future Challenges." Journal of Management 30 (6): 779-804.

Lambert, D. M., and M. C. Cooper. 2000. "Issues in Supply Chain Management.” Industrial Marketing Management 29 (1): 65-83.

Lawrence, P. R., and J. W. Lorsch. 1967. Organization and Environment. Cambridge, MA: Harvard University Press.

Li, J., R. Sikora, M. J. Shaw, and G. W. Tan. 2006. "A Strategic Analysis of Inter Organizational Information Sharing." Decision Support Systems 42 (1): 251-266.

Martin, J. H., and B. Grbac. 2003. "Using Supply Chain Management to Leverage a Firm's Market Orientation.” Industrial Marketing Management 32 (1): 25-38.

Melnyk, S. A., R. Narashiman, and H. DeCampos. 2014. "Supply Chain Design: Issues, Challenges, Frameworks and Solutions." International Journal of Production Research 52 (7): 1887-1896.

Noori, H., and F. Mavaddat. 1998. "Enterprise Integration: Issues and Methods." International Journal of Production Research 36 (8): 2083-2097.

Pagell, M. 2004. "Understanding the Factors That Enable and Inhibit the Integration of Operations, Purchasing and Logistics." Journal of Operations Management 22 (5): 459-487.

Parker, G. G., and E. G. Anderson. 2002. "From Buyer to Integrator: The Transformation of the Supply-chain Manager in the Vertically Disintegrating Firm." Production and Operations Management 11 (1): 75-91.

Pedhazur, E. J., and L. Schmelkin. 1991. Measurement, Design and Analysis: An Integrated Approach. New York: Lawrence Erlbaum Associates.

Porter, M. E. 1980. Competitive Strategy: Technology for Analyzing Industries and Competitors. New York: The Free Press. 
Regli, W. 2007. "The Need for a Science of Engineering Informatics.” Artificial Intelligence for Engineering Design, Analysis and Manufacturing. 21 (1): 23-56.

Roh, J., P. Hong, and H. Min. 2014. "Implementation of a Responsive Supply Chain Strategy in Global Complexity: The Case of Manufacturing Firms." International Journal of Production Economics 147: 198-210.

Rosenzweig, E. V., A. V. Roth, and J. W. Dean. 2003. "The Influence of an Integration Strategy on Competitive Capabilities and Business Performance: An Exploratory Study of Consumer Products Manufacturers." Journal of Operations Management 21 (4): 437-456.

Saeed, K. A., M. K. Malhotra, and V. Grover. 2005. "Examining the Impact of Interorganizational Systems on Process Efficiency and Sourcing Leverage in Buyer-Supplier Dyads." Decision Sciences 36 (3): 365-396.

Sousa, R., and C. A. Voss. 2008. "Contingency Research in Operations Management Practices." Journal of Operations Management 26 (6): 697-713.

Stank, T. P., S. B. Keller, and P. J. Daugherty. 2001. "Supply Chain Collaboration and Logistical Service Performance.” Journal of Business Logistics 22 (1): 29-48.

Stevens, G. C. 1989. "Integrating the Supply Chain.” International Journal of Physical Distribution \& Materials Management 19 (8): 3-8.

Swafford, P. M., S. Ghosh, and N. Murthy. 2008. "Achieving Supply Chain Agility through IT Integration and Flexibility." International Journal of Production Economics 116 (2): 288-297.

Tushman, M. L., and D. A. Nadler. 1978. "Information Processing as an Integration Concept in Organization Design.” Academy of Management Review 3 (3): 613-624.

van der Vaart, T., D. P. van Donk, C. Giménez, and V. Sierra. 2012. "Modelling the Integration-performance Relationship: Collaborative Practices, Enablers and Contextual Factors." International Journal of Operations and Production Management 32 (9): 1043-1074.

Vives, X. 2008. "Innovation and Competitive Pressure." The Journal of Industrial Economics 56 (3): 419-469.

Wang, Z., F. Ye, and K. H. Tan. 2014. "Effects of Managerial Ties and Trust on Supply Chain Information Sharing and Supplier Opportunism." International Journal of Production Research 52 (23): 7046-7061.

Weeks, M. F. 1992. "Computer-assisted Survey Information Collection: A Review of CASIC Methods and Their Implications for Survey Operations." Journal of Official Statistics 8 (4): 445-465.

Wheelwright, S. C., and H. K. Bowen. 1996. "The Challenge of Manufacturing Advantage." Production and Operations Management 5 (1): 59-77.

Winter, S. G. 1990. "Survival, Selection, and Inheritance in Evolutionary Theories of Organization." In Organizational Evolution: New Directions, edited by J. V. Singh: 269-297. Newbury Park, CA: Sage.

Wisner, J. D., and K. C. Tan. 2000. "Supply Chain Management and its Impact on Purchasing." Journal of Supply Chain Management 36 (4): 33-42.

Wong, C. Y., M. M. El-Beheiry, J. Johansen, and H. H. Hvolvy. 2007. "The Implications of Information Sharing on Bullwhip Effects in a Toy Supply Chain.” International Journal of Risk Assessment and Management 7 (1): 4-18.

Wong, C. Y., S. Boon-itt, and C. W. Y. Wong. 2011. "The Contingency Effects of Environmental Uncertainty on the Relationship between Supply Chain Integration and Operational Performance.” Journal of Operations Management 29 (6): 604-615.

Wong, C. Y., K. Lai, and T. C. E. Cheng. 2012. "Value of Information Integration to Supply Chain Management: Roles of Internal and External Contingencies." Journal of Management of Information Systems 28 (3): 161-200.

Xu, L. 2011. "Enterprise Systems: State-of-the-art and Future Trends." IEEE Transactions on Industrial Informatics 7 (4): 630-640.

Xu, L. 2014. "Engineering Informatics: State of the Art and Future Trends." Frontiers of Engineering Management 1 (3): $270-282$.

Yu, W., and R. Ramanathan. 2015. "An Empirical Examination of Stakeholder Pressures, Green Operations Practices and Environmental Performance.” International Journal of Production Research 53 (21): 6390-6407.

Zahra, S. A., and J. G. Covin. 1995. "Contextual Influences on the Corporate Entrepreneurship-performance Relationship: A Longitudinal Analysis.” Journal of Business Venturing 10 (1): 43-58.

Zhou, K. Z., Q. Zhang, S. Sheng, E. Xie, and Y. Bao. 2014. “Are Relational Ties Always Good for Knowledge Acquisition? Buyer-Supplier Exchanges in China." Journal of Operations Management 32 (3): 88-98. 